\title{
A política segundo os princípios da Doutrina da ciência
}

Marco Rampazzo Bazzan

\section{(2) OpenEdition}

Journals

Edição electrónica

URL: https://journals.openedition.org/ref/1665

DOI: $10.4000 /$ ref. 1665

ISSN: 2258-014X

Editora

EuroPhilosophie Editions

Refêrencia eletrónica

Marco Rampazzo Bazzan, «A política segundo os princípios da Doutrina da ciência», Revista de Estud(i)os sobre Fichte [Online], 21 | 2020, posto online no dia 01 dezembro 2020, consultado o 04 março 2022. URL: http://journals.openedition.org/ref/1665 ; DOI: https://doi.org/10.4000/ref.1665

Este documento foi criado de forma automática no dia 4 março 2022

(C) EuroPhilosophie 


\title{
A política segundo os princípios da Doutrina da ciência
}

\author{
Marco Rampazzo Bazzan
}

\section{Introdução}

Explicitada ou não como tal uma questão substantiva sempre ronda os estudos sobre o pensamento político de Johann Gottlieb Fichte. É a questão de saber se, com a Doutrina da ciência, foi ou não aberto um novo entendimento da política. Pois, não cabe a menor dúvida que a grande ambição de Fichte foi formar uma nova maneira de olhar não apenas a ciência (Wissenschaft) ou o saber (Wissen) em geral - isso é a tarefa explicita da Doutrina da ciência in specie - mas também as ciências particulares e todo saber determinado. No intuito do filosofo, a expressão "segundo os princípios da Doutrina da ciência" - que aparece nos títulos de suas obras sobre o direito natural (1796-1797) e a moral (1798) - significava, ambicionava e prometia justamente um novo entendimento a ser engendrado e formado no ouvinte (ou no leitor) sobre o assunto em questão. $\mathrm{E}$ este novo entendimento não deveria ser tomado como um fim em si mesmo senão como a condição de uma atuação plenamente moral que o filosofo chama de sabedoria (Weisheit), ${ }^{1}$ ou "moral superior". ${ }^{2}$

Porém, a política é um assunto sobre o qual Fichte não nos deixou nenhum tratado sistemático. Destarte, para respondermos à questão levantada, não temos outra opção a não ser percorrer as definições mais significativas de política espalhadas em seus escritos e conferências, por um lado; e considerar seu próprio engajamento tanto na teoria quanto na prática enquanto homem de cultura, por outro. A leitura atenta dos textos de Fichte evidencia que, em seu pensamento, a política pode ser entendida não apenas como a teoria do Estado (Staatslehre) ou a arte do governo (Regierungskunst) - o que poderíamos chamar de política stricto sensu - mas também como o principal efeito social da arte de filosofar. Nesta ótica, haveria de se chamar "político" a todo efeito da exortação (Aufförderung) ${ }^{3}$, na qual o filosofo colocava a interação intersubjetiva fundamental para o homem poder se formar na vida ética, e, assim, realizar seu destino 
(Bestimmung) - o que propomos aqui chamar de política lato sensu. Sendo assim, a política segundo os princípios da Doutrina da ciência definiria não apenas uma ciência (ou técnica), senão muito mais uma prática ou arte (Kunst) de viver ${ }^{4}$ em sociedade.

\section{O âmbito da política a partir do Fundamento do direito natural}

Há quarenta anos, discutindo a conferência que Manfred Hahn acabava de pronunciar sobre o conceito de política em Fichte (Fichtes Politik Begriff), Richard Schottky levantou uma pergunta que traz à tona uma primeira questão a ser analisada para esclarecermos nosso assunto. Trata-se da relação problemática entre a concepção de Fichte acerca do direito e da política por um lado, e a ciência política dominante em seu tempo pelo outro.

Haveria duas opções para se discutir sua fala. Primeiramente, poder-se-ia questionar se o espaço de liberdade que, em Fichte, se deixa para o indivíduo no Estado não tenha sido apresentado de uma forma um pouco sucinta. Além disso, o que me parece mais importante, poder-se-ia levantar a questão de se as aporias que foram apontadas de forma tão perspicaz na fala haveriam de ser imputadas a Fichte ou se elas não lidariam, ao invés, com a essência da coisa. ${ }^{5}$

Não cabe a menor dúvida que "a essência da coisa" evocada por Schottky seja a lógica aporética elaborada no seio das doutrinas modernas do contrato social ao longo da idade moderna. ${ }^{6}$ Contudo, foi justamente Schottky o primeiro pesquisador que estudou a relação do pensamento de Fichte com as doutrinas modernas do direito natural, cujo paradigma lógico se encontraria no Leviatã de Thomas Hobbes. ${ }^{7}$ Para nós, a questão torna-se a de saber se Fichte trilharia esse caminho em prol de um novo entendimento da política, ou se, pelo contrário, sua proposta não acabaria por reproduzir as aporias típicas jusnaturalismo moderno tal como essas se apresentam no direito público prussiano do Século Dezoito. ${ }^{8}$

Antes de tudo cabe ressaltar que, na discussão entre Hahn e Schottky, o conceito de política é analisado e discutido desde o ponto de vista sistemático da doutrina do direito. Na verdade, este recorte não é em nada arbitrário na medida em que decorre diretamente da definição de política que Fichte apresenta no parágrafo 21 do Fundamento do direito natural segundo os princípios da Doutrina da ciência. Em 1797, o filosofo alemão define a política: "a ciência que tem que ver com um Estado particular determinado por características contingentes (empíricas) e que considera qual é a maneira mais conveniente de nele realizar a lei do Direito" (GNR, GA I/4, 80/FDN, 341). ${ }^{9}$

De acordo com esta definição, o âmbito da ciência política consiste na realização do direito. Destarte, de um ponto de vista simplesmente formal ou nominal a questão de se, e como sua definição de política constituiria uma inovação em relação à concepção codificada no direito público prussiano, a resposta imediata não poderia ser senão negativa. Pois, no contexto das "Ciências do Estado" (Staatswissenschaften), entende-se sob política justamente a aplicação (Anwendung) ou realização (Verwirklichung) do direito. ${ }^{10}$

Sendo assim, a relação entre direito e política, que o filosofo apresenta em 1797, assume como ponto de partida o entendimento da segunda a partir do direito público prussiano. Porém, no caso de Fichte, a retomada literal de uma definição corrente de política não deveria levar o leitor ou comentador a concluir com demasiada rapidez que 
o intuito do filosofo (ou o êxito do Fundamento do direito natural) seria simplesmente reproduzir as figuras ou categorias da ciência política dominante em sua época. $\mathrm{Na}$ verdade, o fato de que não haja inovação no plano nominal ou na letra das formulações decorre diretamente do filosofar segundo os princípios da Doutrina da ciência. Como destaca Rubens Torres Filho, "a linguagem pressupõe sempre [...] em seu destinatário o ativamento daquela mesma 'fantasia' que permite ao homem antes de toda linguagem, pensar e ter conceitos gerais e abstratos. É a essa livre produção de imagens que compete proceder à reconstrução da significação, condição de toda compreensão". ${ }^{11}$ Sendo assim, de acordo com o comentador brasileiro, "deixar as palavras é a condição prévia da doutrina da ciência na medida em que é a condição de toda compreensão" (Torres Filho 1973, 23). Com efeito, a doutrina da ciência é uma reflexão transcendental sobre os conteúdos da consciência imediata. Ela sempre pressupõe um conteúdo já dado (isto é, linguisticamente formado) que constitui o posicionamento contingente ou a crença comum (ou dominante), isto é, a base factiva para o engendramento da reflexão transcendental.

Ora, no tocante às ciências particulares, o ponto de partida desta reflexão não pode ser senão conteúdo do que uma determinada época considera como verdadeiro (als wahr haltet) no assunto em questão. ${ }^{12}$ No Sistema de Ética de 1798, Fichte define este tipo de crença como "símbolo": enquanto fundamento da crença no supersensível de uma comunidade dada, isto é, "sua profissão de fé" (SSL, GA I/5, 218). Com base nestas considerações, podemos concluir que a ciência de um determinado tempo histórico define o simples ponto de partida da reflexão transcendental, ${ }^{13}$ ou seja, a posição ou fato que a filosofia como doutrina da ciência pretende genetizar (ou fundamentar), tendo como objetivo formar uma nova atitude ética e critica. ${ }^{14}$

Apesar de ser um aspecto geralmente pouco considerado no âmbito dos estudos fichteanos, cabe lembrar o fato de que, no Fundamento do direito natural, o filosofo expõe para seus alunos uma disciplina cientifica perfeitamente codificada. ${ }^{15}$ Como na maioria das obras publicadas, também aqui, o objetivo principal da publicação é fornecer para os alunos um compêndio do que o filosofo apresentou em suas aulas, neste caso, sobre o direito natural durante o semestre invernal de 1795. Isto posto, vale a pena perguntarmo-nos qual poderia ser o intuito ou objetivo efetivo de Fichte ministrando um curso sobre o Fundamento do direito natural segundo os princípios da doutrina da ciência na Universidade de Jena. Uma resposta implícita encontra-se no Sistema de Ética de 1798 , onde o autor define a tarefa dos eruditos em relação às ciências existentes. De acordo com ele, os eruditos (verdadeiros) deveriam "fazer progredir o conhecimento atual" (SSL, GA, I/5, 302). No caso de Fichte, este progresso exige uma retificação a partir de uma nova fundamentação dos princípios da ciência em questão. Ademais, para poder cumprir sua tarefa, o (verdadeiro) erudito deveria "conhecer historicamente o curso da ciência e os princípios que ela utilizou até seu tempo" (SSL, GA, I/5, 302). Com base nestas considerações, podemos conjeturar que o objetivo específico do Fundamento do direito natural é retificar a ciência existente para que seus alunos, ou seja, futuros eruditos, educadores morais, artistas ou servidores públicos venham formar um novo entendimento do direito e da política, e assim agirem em prol de um progresso efetivo das Luzes.

A esta altura trata-se de entender como este intuito pratico - o de formar um novo entendimento, criticando "as verdades estabelecidas" da ciência dominante orientaria efetivamente a obra de 1796-97. Conforme a tarefa de "conhecer 
historicamente o curso da ciência" e os princípios que a regiam até então, em vista do curso que inicia em 20 de outubro de $1795^{16}$, Fichte realiza um estudo preparatório que inclui os ensaios de Kant (entre os quais a Religião entre os limites da simples razão e a Paz perpetu $\left.a^{17}\right)$ e os artigos sobre o direito natural publicados no Philosophisches Journal em 1795 (GA II/3, 395-406). ${ }^{18}$ Com base neste estudo preliminar, na Introdução ao Fundamento do direito natural, o filosofo conceitualiza uma distinção substantiva entre duas maneiras de filosofar. Trata-se da distinção entre a "ciência filosófica real" (ou verdadeira) e a "filosofia de fórmulas". o espírito filosófico diferenciar-se-ia do pensamento natural pelo fato de "achar em e durante o atuar mesmo, não apenas o que surge naquilo, senão também o atuar como tal" (GRN, GA I/3, 316/FDN, 9). Por um lado, há o "filosofo de fórmulas" que:

pensa para si isso e aquilo, se observa a si mesmo neste pensar e apresenta como verdade a série completa daquilo que foi capaz de pensar, simplesmente porque o pôde pensar. $O$ objeto da sua observação é ele próprio, tal como procede livremente, seja sem qualquer direção, ao acaso, ou segundo uma meta que lhe é dada de fora (GRN, GA I/3, 316/FDN, 9).

Assim, ele observaria a si como individuo particular e sua observação seria contingente e arbitraria. Pelo outro, há o "filosofo verdadeiro" que observa "a razão no seu proceder originário e necessário, mediante o qual existe o seu Eu e tudo o que para ele existe" (GRN, GA I/3, 316-317/FDN, 9-10). O objeto de sua observação é, por conseguinte, a razão em geral; sua observação procede necessariamente segundo suas leis internas, sem nenhuma finalidade externa.

A partir destes elementos, nossa hipótese é que, fundamentando o direito natural segundo os princípios da doutrina da ciência, Fichte pretende criticar e genetizar os princípios e as formulações de uma disciplina codificada, isso é, o direito natural no contesto do direito público prussiano. Sendo assim, propomos entender a distinção entre ciência filosófica real e filosofia de fórmulas como a linha divisória pela qual o filosofo alemão ambiciona diferenciar sua exposição em relação aos tratados habituais, ou seja, retificar a doutrina do direito natural cumprindo a tarefa de "fazer progredir" esta ciência particular.

\section{A arte da política}

Ora, temos que entender qual seria o princípio norteador dessa ressemantização da doutrina do direito natural segundo os princípios da doutrina da ciência. Como já adiantamos, a perspectiva teórica de Fichte decorre do princípio segundo o qual os eruditos deveriam "fazer progredir o espírito da comunidade mediante essa retificação do conhecimento" (SSL, GA I/5, 302) e que a filosofia existiria propriamente na medida em que o discurso do falante engendra nos ouvintes um novo entendimento da ciência em questão. Falando do "espectro filosofante" no Destino do Homem, Rubens Torres Filho ressalta que, para Fichte, o objetivo de toda exposição era: "conduzir seu interlocutor a engendrar em si mesmo um pensamento que ele próprio já havia engendrado, e não para transmiti-lo, que aquele 'Espírito' maravilhoso e raciocinante lhe dirigia um certo discurso; e era a partir do pensamento engendrado em sua própria consciência que seu ouvinte reencontrava a expressão" (TORRES FILHO, 1973, 10). Esse espírito é justamente o que está em jogo numa reflexão ou prática filosófica segundo os princípios da Doutrina da ciência. Utilizando uma expressão típica do Fichte berlinense, trata-se da formação de uma "vista própria" (eigne Sicht) (SL 1812, GA II/13, 384). 
Ora, o engendramento de um pensamento livre e autônomo, no qual consiste a existência do filosofar, pode ser entendido como efeito de uma exortação (Aufförderung). A exortação é uma figura teórica substantiva que Fichte apresenta em 1796 e sua importância decorre do papel fundamental que desempenha tanto na ressemantização (ou ressignificação) do direito quanto na educação segundo os princípios da Doutrina da ciência. Sob o primeiro aspecto, o princípio do direito é estabelecido a partir da noção de "relação jurídica", isso é: "a relação entre seres racionais [...], a saber, que cada um limite a sua liberdade pelo conceito da possibilidade da liberdade do outro, na condição de que este limite igualmente a sua liberdade pela do outro" (GNR, GA I/3, 358/FDN, 63). Sob o segundo, esta relação configura uma influência recíproca dos sujeitos envolvidos. De acordo com Fichte: "o conceito de Direito só vale para pessoas que podem encontrar-se e que efetivamente se encontram numa relação de influência recíproca no mundo sensível" (GNR, GA I/4, 57 /FDN, 307). Diferenciando-se da causalidade mecânica que caracteriza o mundo sensível, a exortação expressa uma determinação "do sujeito para a autodeterminação" (GNR, GA I/3, 342/FDN, 41). Esta determinação decorre de uma "exortação ao sujeito para agir" (GNR, GA I/3, 342/FDN, 41). Uma tal "exortação ao sujeito a uma atividade livre" configura justamente uma "influência" recíproca que permite ao homem exercer sua capacidade de se transformar (Bildsamkeit) ${ }^{19}$, tendo um conceito de fim, e, idealmente, realizando sua natureza suprassensível ou moral. Como destaca Günter Zöller, a exortação que se endereça ao ser racional e livre, baseia-se, por parte do ser que exorta, enquanto ele atua de maneira livre e racional, num ato cognitivo e volitivo. ${ }^{20}$ Destarte, a exortação não pertence às relações de ação e repulsão que regem mecanicamente o mundo sensível. Pelo contrário, seu âmbito é a esfera intelectual na medida em que se expressa "através de signos que não comandam, senão que iniciam o uso racional autônomo da liberdade do outro que se exorta" (ZÖLLER 2015, 57).

Sendo assim, podemos entender a exposição do direito natural segundo os princípios $d a$ Doutrina da ciência como um conjunto sistemático de exortações aos ouvintes ou leitores para que possam formar um novo olhar sobre as categorias que ela "fundamenta" e articula. Como Fichte mesmo esclarece no curso de Doutrina de direito de 1812, o desafio frente às concepções habituais (verwöhnlich) consistiria em entender o direito enquanto um "conceito vivo que há de se formar" (RL1812, GA II/13, 222). Trata-se de um conceito a ser engendrado a partir das circunstâncias dadas, ou seja, levando em conta a concepção dominante por um lado, e a conjuntura político-econômico-social por outro. Para entendermos toda a importância da observação mencionada acima, cabe lembrar que, à época, o direito natural era considerado como uma "ciência pura e verdadeira" (RL1812, GA II/13, 197). Era a ciência que fundamentava racionalmente a obediência ao Estado, ou seja, o princípio de legitimidade do poder público. ${ }^{21} \mathrm{O}$ dispositivo teórico do contrato social encenava um processo de autorização para o governo do rei e, assim, legitimava ideologicamente as diferenças instituídas pelo direito histórico, isto é, “o direito do mais forte". Para nós, Fichte entende justamente este dispositivo como o "conceito morto" do direito, do qual ele pretende justamente diferenciar sua elaboração.

Ora, na Prússia de 1795, o direito positivo era regido pelo Allgemeines Landrecht für die Preussischen Staaten. Este Código geral foi o resultado de um longo processo que envolveu toda a família real prussiana, os Höhenzollern, ao longo de todo o Século Dezoito. Em 1714, Frederico Guilherme I, pela primeira vez, ordenou que a Faculdade de direito da Universidade de Halle a redigir um código geral com o objetivo de 
uniformizar o direito romano e os vários direitos dos territórios (Länder) que constituíam o Reino de Prússia. Federico II retomou o projeto de seu pai no final de seu próprio reinado. Em 14 de outubro de 1780, o monarca ordenou, ao novo Chanceler Cramer, a estabelecimento do Código geral. Depois da morte de Frederigo o Grande, a Comissão pela reforma da justiça, liderada por Carl Gottlieb Suarez e Ernst Ferdinand Klein, procura envolver no projeto toda a comunidade de juristas prussianos através de convites e prêmios públicos. Com base nos pareceres recebidos, a comissão elabora uma primeira versão que será publicada em 1792 (sem entrar em vigor) sob o título de Allgemeine Gesetzgebung e sob o reinado de Frederico Guilherme II. Esta versão será logo discutida e atualizada com a publicação, com força de lei, do Allgemeines Landrecht em 1794.

Ora, o Código geral não era apenas um apanhado do material jurídico existente, pois sua vocação principal era desempenhar uma função constituinte. Através do Código, "a expressão imediata da vontade reguladora soberana pretendia articular toda a sociedade prussiana". ${ }^{22} \mathrm{Em} \mathrm{1792,} \mathrm{Suarez} \mathrm{foi} \mathrm{convocado} \mathrm{para} \mathrm{ministrar} \mathrm{lições} \mathrm{privadas} \mathrm{ao}$ futuro rei Frederico Guilherme III. Neste contexto, o jurista apresenta ao futuro monarca o dispositivo ideológico que inspirava o Código geral. o jurista coloca a origem histórica do Estado no "direito do mais forte", ou seja, na violência, e atribui à teoria do direito natural a tarefa de fornecer uma "sanção" da ordem da sociedade existente. Com outras palavras, o contrato é declaradamente uma fiç̧ão que deveria não apenas orientar o governo do monarca, mas também, acima de tudo, justificar racionalmente a obediência de seus súditos. ${ }^{23}$

Nesta ótica, as colocações mencionadas de Suarez permitem destacar um ponto decisivo que constitui o centro de muitos debates acerca do direito público na última década do Século Dezoito. Desde um ponto de vista formal, todos os juristas ou filósofos políticos estavam de acordo acerca dos princípios do direito natural, suas divergências manifestavam-se, em contrapartida, a respeito das consequências dos princípios que aí encontravam expressão jurídica: justificar o status quo ou fundamentar uma nova ordem civil? o posicionamento de Fichte frente a esta alternativa fica muito claro desde 1793. O direito esclarecido pela razão exige a construção de uma ordem social justa, ou seja, uma transformação da sociedade existente (SSL, GA I/5, 223). Nos cursos berlinenses, falando da doutrina do direito, Fichte declara várias vezes seu intuito a seus ouvintes: formarem uma visão diferente daquelas que as "maneiras habituais"

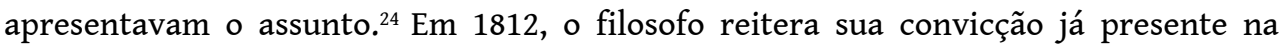
compreensão do Estado como "meio para um fim" (Mittel zum Zweck) ${ }^{25}$. Se a doutrina do direito, historicamente, fornece uma justificativa e uma inteligência da relação de comando-obediência entre governo e governados, tal como existe enquanto resultado dos processos históricos contingentes e fortuitos, sua compreensão pela doutrina da ciência pretende articular uma "lógica pragmática" (RL1812, GA II/13, 198) que hoje se pode chamar de performativa: Se todos querem coexistir como seres livres numa sociedade baseada no direito conforme à razão eles devem participar da construção de uma ordem civil consoante a isso, ou seja, o fim da sociedade é a instauração da igualdade efetiva entre seus cidadãos. Em suma, a ressemantização das categorias jurídicas da ciência política segundo os princípios da Doutrina da ciência tem como princípio norteador a ideia de que a obediência dos governados há de se justificar apenas pela ação do governo que deve perseguir de forma clara (sob o juízo do público esclarecido) o objetivo de que a liberdade ética venha a ser realizada, isto é, possibilitar o progresso das Luzes. ${ }^{26}$ 


\section{As duas significações de política}

Em acordo com a definição de 1797, a política como realização do direito há de levar em conta a conjuntura, ou seja, o contexto histórico. O Fundamento do direito natural segundo os princípios da doutrina da ciência apresenta e articula os princípios que haveriam de orientar a política tanto no tocante à exposição cientifica desta disciplina, quanto no tocante à realização efetiva do que Fichte chama de "direito de razão" (Vernunftrecht) (cf. RL1812, GA II/3, 199). Com base na classificação contida nas Prelações sobre o destino do erudito de 1794 (BG, GA 1/3, 53), que anunciam sob vários aspectos o curso de $1795^{27}$, a política encontraria seu lugar sistemático sistemática no plano das ciências históricofilosóficas (escolha dos meios empíricos em vista da realização de finalidades puramente racionais). Ao mesmo tempo, a doutrina do direito é um saber "pragmático" na medida em que esclarece as condições práticas de existência de um Estado ou Império da razão (Vernunftsreich). Por um lado, ela constitui um critério para julgar e avaliar os Estados existentes e, por outro, define a ideia que deveria orientar a ação do governo em prol de sua realização racional. ${ }^{28}$

As aporias evocadas por Schottky na discussão com Hahn lidam basicamente com a antítese entre liberdade natural e direito de coação (que consiste numa privação aparente dessa liberdade), que, em acordo com Fichte, define a problemática central da doutrina do direito stricto sensu, objeto dos parágrafos 8-16 do Fundamento do direito natural segundo os princípios da Doutrina da ciência (GRN, GA I/3, 389-460/FDN, 111-340). Para além disso, a antítese entre liberdade e coação caracteriza a problematicidade da posição intermediaria (entre natureza e moral) ${ }^{29}$ que o filosofo assinala ao direito em seu sistema desde 1796 até as conferências ministradas em 1813. Na "Introdução geral" dessas conferências publicadas postumamente em 1820, sob o título de Doutrina do $E s t a d 0^{30}$, ele define o horizonte prático (e não teórico) no qual se coloca sua reflexão. De acordo com Fichte, o direito se realizou historicamente até um ponto determinado, ou seja, parcialmente ou de maneira imperfeita (Staatslehre, GA II/16, 33). Nesta medida, o enfoque de sua reflexão política lida com a parte da ideia do direito a ser realizada. Para entender toda a importância desta perspectiva prática, cabe ressaltar que a condição decisiva para se decidir sobre a legitimidade de um governo ou de um aparelho de Estado, ou seja, se os governados devem ou não obedecer à autoridade pública, não se situaria no âmbito a priori do direito (conforme a lógica da autorização) senão naquele $a$ posteriori da política (do reconhecimento da ação do governante por parte da opinião pública esclarecida)..$^{31}$

Em acordo com nossa hipótese, Fichte procura dinamizar e transformar semanticamente as categorias jurídicas codificadas pelas doutrinas do direito natural em geral, e do direito público prussiano em particular. A partir da Introdução de 1796 seu intuito é substantivar as categorias do direito conectando-as com determinadas ações do espírito. A figura emblemática deste gesto fundamental é a exortação que define, ao mesmo tempo, o conceito de relação jurídica e o processo de aprendizagem. ${ }^{32}$ De fato, ao não se efetivarem as ações que transformam semanticamente as categorias jurídicas tradicionais, o direito permanece como um "conceito morto" (cf. RL1812, GA II/13, 222). Sendo assim, o princípio que norteia a exposição de Fichte é que direito é apenas o que existe como direito positivo. Ou seja, direito é só o que se realiza como tal. Agora, se direito é apenas o que se efetiva como tal e se a política é a realização do 
direito, pode se concluir que direito é o que a política realiza como direito vigente. $\mathrm{E}$ isso representa, de fato, uma completa inversão, isso é, uma subversão da concepção dominante acerca deste assunto.

Ora, Fichte apresenta uma segunda definição de política na Introdução do Estado comercial fechado de 1801. A política seria a "ciência do governo (Regierungswissenschaft) do Estado real conforme a máxima seguinte" "quanto do que seria justo (rechtens) é realizável nas condições dadas". Assim, a política "está no meio entre o Estado existente (gegebenen Staate) e o Estado conforme à razão (Vernunftsstaat)" e "descreve a linha continuada pela qual o estado existente se transforma no Estado de razão e, enfim, no puro Estado de direito" ( $g H S, G A ~ I / 7,51)$. Com base nesta definição, podemos então distinguir dois conceitos de política: uma política stricto sensu que tem a ver com a arte do governo, e uma política lato sensu que tem a ver com a transformação do Estado existente tendo como fim a realização da ideia de direito. Isto posto, a política lato sensu vai coincidir com o progresso efetivo das Luzes. Este progresso define a tarefa principal (ou destino verdadeira) do público erudito.

A partir da Reivindicação da liberdade do pensamento até a Doutrina do Estado, o progresso das Luzes é o princípio norteador da visão política de Fichte. A existência efetiva deste progresso constitui a conditio sine qua non para a legitimidade de um Estado. De maneira significativa, em 1812, o filosofo coloca a distinção entre despotismo e o Estado do direito na existência de instituições que viabilizem a educação pela liberdade. Sob vários aspectos, o título das Contribuições para retificar o julgamento do publico alemão sobre a Revolução Francesa, obra publicada anonimamente entre 1793 e 1794, resume perfeitamente a dimensão política das atuações públicas de Fichte. Para o filosofo, sua própria atividade enquanto homem de cultura consiste em produzir exortações em prol da formação de um julgamento livre e racional por parte do público. Dito com outras palavras, suas intervenções são exortações para o público pensar por si mesmo.

Contudo, na Introdução das Contribuições, o autor justifica sua intervenção pela necessidade de ajudar o público diante do novo desafio representado pela popularização de assuntos que até então foram discutidos só por especialistas. Trata-se dos "direitos humanos sobre liberdade e igualdade, sobre a santidade dos contratos e dos juramentos, sobre os fundamentos e os limites dos direitos do rei" (BB, GA I/3, 204-205), ou seja, as categorias das doutrinas do direito natural que foram popularizadas pela Declaração dos direitos do Homem e do Cidadão de 1789. Sendo assim, podemos entender a intervenção de Fichte como uma resposta aos processos que, de acordo com Koselleck, caracterizam a formação dos conceitos políticos modernos, em particular sua "popularização" e "ideologização"33.

Ora, em 1793, Fichte apresenta-se para seu leitor como um "amigo" que pode ajudar seu ouvinte a engendrar e desenvolver uma visão própria sobre esses assuntos. Desta maneira, Fichte politiza os códigos da comunicação erudita, desenvolvidos e codificados nos debates públicos no âmbito estético. Neste contexto a decisão de uma controvérsia não decorre de um processo de autorização (conforme ao princípio hobbesiano Auctoritas non veritas facit legem), senão pela formação de um julgamento com vocação universal, impulsado pelo convencimento do público. ${ }^{34}$ Sob esta ótica é fácil de reconhecer como a contribuição de Fichte se pauta pela definição kantiana do Esclarecimento. Seu alvo polémico são justamente os "preconceitos" e a "inercia do espírito" que caracterizam a opinião pública. $\mathrm{O}$ desafio se torna, por conseguinte, a formação de um entendimento adequado, isto é, não apenas formalístico, dos direitos 
proclamados universalmente na Declaration de Droits de l'Homme e du Citoyen, e que constitui o verdadeiro alvo polêmico da crítica de Rehberg. ${ }^{35}$

Para legitimar plenamente nossa leitura da política segundo os princípios doutrina da ciência cabe ressaltar o que Fichte entendia o estabelecimento do contrato social, e quem considerava como os assinantes concretos desse contrato. Mais uma vez, uma resposta pode ser encontrada no Sistema de Ética: "O contrato social, na medida em que por isso se estabelecem os direitos recíprocos sobre as pessoas, não foi feito pelos indivíduos, mas pelos Estamentos" (SSL, GA I/5, 311-312). De fato, no Allgemeines Landrecht, o contrato pretendia expressar a vontade de todos os cidadãos. Na verdade, este acordo podia se expressar apenas tacitamente, enquanto os direitos eram definidos a partir do nascimento (isto é, em relação aos estamentos). Este detalhe evidencia a dimensão ideológica do Código geral: seu objetivo era apenas justificar racionalmente o direito histórico e suas desigualdades. $O$ ponto decisivo para nossa argumentação encontra-se na maneira pela qual Fichte admite uma reforma da constituição vigente. $O$ magistrado que administra o poder executivo poderia e deveria modificar a constituição apenas no caso em que a comunidade provasse ter um entendimento diferente (superior no sentido de mais conforme à razão) do direito. Com outras palavras, o fundamento da constituição civil decorre do entendimento geral e efetivo acerca do direito por parte da comunidade de cidadãos. Sendo assim, o contrato social constitui apenas o símbolo, isto é, a crença determinada da comunidade em questão sobre as relações jurídicas. Destarte, o contrato social não é um princípio válido eternamente (a priori), senão simplesmente o princípio que se acredita geralmente como justo e verdadeiro apenas na época de Fichte.

Ora, não cabe a menor dúvida de que o agente principal do progresso das Luzes seja o público erudito. Em 1798, o filosofo define o público erudito como "um fórum de uma consciência comunitária diante da qual se pode pensar e examinar todo o possível com uma liberdade absoluta e ilimitada" (SSL, GA I/5, 223). A condição para realizar este progresso é que os membros desta sociedade particular tenham se desprendido das "ataduras do símbolo eclesiástico e dos conceitos jurídicos sancionados pelo Estado", isso é, do direito vigente (SSL, GA I/5, 223). As doutrinas do direito natural ou público da época tornam-se o objeto a ser geneticamente analisado, isto é, a crença dominante sobre direito e política da comunidade. Como adiantamos acima, em sua exposição, Fichte tem como objetivo que seus alunos possam formar um novo entendimento deste assunto. Ele é ciente de que, entre seus alunos, estão os futuros eruditos, educadores do povo, artistas e funcionários públicos. Todos eles desempenharão um papel fundamental na formação da opinião pública. Numa palavra, o objetivo do filosofo é formar aqueles que participarão do público erudito no porvir.

Através de exortações, o publico erudito atua na sociedade influenciando a formação da opinião pública, ou seja, o entendimento geral por parte da comunidade acerca do fundamento da sociedade. De acordo com a definição kantiana, Fichte defende a ideia do Esclarecimento como educação e formação lato sensu. A formação se efetiva através de uma influência recíproca entre os indivíduos em sociedade. Esta influencia não se deve entender por doutrinamento, senão como engendramento de um pensamento autônomo e singular, impulsado por uma exortação por parte de seres livres e racionais. A dinâmica política tem como objetivo que a lei vigente possa coincidir com o que a comunidade entende por seu símbolo, isto é, seu fundamento espiritual. Por "comunidade", Fichte entende uma subjetivação determinada do povo, e esta 
subjetivação recupera as características do estado de natureza ético descrito por Kant na Religião dentro os limites da simples razão. ${ }^{36}$ Nesta perspectiva, o público erudito desempenha um papel substantivo na modificação da lei fundamental ou constituição jurídica e, por conseguinte, também na dinâmica eminentemente política de uma sociedade.

\section{Conclusão: a política e a função do Legislador}

Em 11 de junho 1812, ao concluir o curso sobre a doutrina do direito, Fichte observa que: "enquanto o governo não vier a ser bom, a maioria sempre será ruim. Uma boa maioria depende de um bom governo" (RL1812, GA II/13, 285). Como vimos anteriormente, um progresso moral efetivo da sociedade decorre de um entendimento mais esclarecido (ou superior) acerca do fundamento e da finalidade da relação entre os seres racionais que formam uma determinada comunidade. A formação desse entendimento é possível apenas pela ação virtuosa por parte tanto do governo quanto do público erudito em prol de uma influência recíproca emancipadora. Sendo assim, a questão do direito encontra sua solução efetiva apenas no plano prático da política.

Ora, na visão negativa ou pessimista sobre a sociedade de seu tempo em 1812, podemos ressaltar uma correspondência profunda com as considerações críticas de Rousseau nos primeiros dois Discursos. No final do Discurso sobre as artes $e$ as ciências, Rousseau destacava que "enquanto o poder estiver só de um lado, e as luzes e a sabedoria só do outro, os sábios raramente pensarão em grandes coisas, os príncipes mais raramente farão de belas e os povos continuarão vis, corruptos e infelizes." ${ }^{37} \mathrm{~A}$ crítica à ideia de um retorno ao estado de natureza primitivo que Fichte apresenta na Quinta Prelação sobre o destino do erudito não prejudica seu acordo com o diagnóstico rousseuaiano acerca da corrupção da sociedade de seu tempo. Contudo, Fichte pretende elaborar uma solução diferente. ${ }^{38}$ Para ele, Rousseau "derramou o fogo em muitas almas, que levaram mais longe o que ele iniciou. Mas agiu quase sem ser consciente da sua autoatividade. Agiu sem chamar os outros à ação, sem avaliar a ação destes perante o conjunto do mal e da corrupção comuns" (BG, GA I/3, 67). Numa palavra, Rousseau denunciou e agiu sem exortar aos outros pensarem e atuarem livremente. Como destacamos, para Fichte, a formação de uma comunidade esclarecida pela ação do público erudito constituiria o verdadeiro poder constituinte para reformar a sociedade existente em prol da instituição do Império da razão.

Ora, um governo é legitimo apenas se fomenta o desenvolvimento de um público erudito capaz de liderar o progresso das Luzes. Mas, conforme a definição de 1798, por público erudito não há de se entender o simples conjunto dos eruditos de profissão, senão uma função social. Na verdade, esta função parece muito próxima daquela que se atribui ao legislador no Contrato social. No capítulo VII do Segundo livro, Rousseau destaca que o legislador deve ser extraordinário "por seu gênio, mas igualmente por sua função". Esta função seria extraordinária enquanto extraconstitucional. Pois, Rousseau sustenta, "essa sua função que constitui a república, não integra, porém, a constituição desta", destacando claramente que "não se trata de magistratura, não se trata de soberania" ${ }^{39}$.

Em 1796, Fichte critica a divisão entre poder legislativo e poder executivo proposta por Kant. Nesta critica, ele ressalta o primado do poder executivo conforme ao princípio de que uma lei existe só se tem um poder que impõe seu respeito. Neste contexto, Fichte 
propõe o Eforato como "parte essencial de qualquer Constituição" (GRN, GA I/3, 328/ FDN, 21). "A norma fundamental de toda a Constituição política conforme à razão e ao Direito" seria:

o poder executivo (que compreende, como poderes inseparáveis, o poder judicial e o poder executivo em sentido estrito) esteja separado do direito de inspecionar e de julgar sobre o modo como o poder executivo é administrado, direito esse a que proponho chamar eforato, no sentido mais amplo do termo (GRN, GA I/3, 440/FDN, 190-191). ${ }^{40}$

Porém, em 1812, Fichte descarta a opção constitucional do eforato porque considera a sociedade de seu tempo demasiado corrupta para permitir o bom funcionamento desta instituição. Contudo, ele ressalta também que o eforato se efetivaria onde exista um público erudito, isso é: "onde se desenvolve um pensamento acerca do governo e sua conduta, aí realiza-se um eforato que observa" e que pode cumprir com duas tarefas fundamentais já destacadas em 1796, ou seja: advertir o governo, caso sua conduta contrarie o direito, e convocar o povo, caso o governo, ignorando essa advertência, persevere em ações contrárias ao direito. Sem poder aqui entrar nos detalhes desta consideração, cabe apenas destacar como o papel eminentemente político que Fichte reconhece ao público erudito se aproxima da função do legislador rousseauiano. Em ambos os casos, trata-se de "mudar, por assim dizer, a natureza humana" (Rousseau 2016, 92) ${ }^{41}$. O Legislador é a figura 1) que abre a instituição de um povo - o que em Fichte se pensa como subjetivação da comunidade -; 2) que permite a conscientização da vontade e do interesse gerais por parte de uma comunidade - o que em Fichte se pensa com a nova fundamentação do direito natural para os futuros membros do público erudito -; e que "cuida em segredo" da opinião (Rousseau 2016, 107) o que em Fichte corresponde à formação (e retificação) do julgamento do público.

Ora, a ação do Legislador é eminentemente política, isso é, extraconstitucional, por conseguinte, ela se situa para além do sistema de garantias formais, definido pelo direito positivo. De acordo com Rousseau, a autoridade do legislador é de "outra ordem" (2016, 94), ou seja, ela não decorre do processo de autorização, configurado pelo dispositivo jusnaturalista forjado teoricamente por Hobbes, e realizado pela vontade de Federico Segundo na Prússia, com o Código Geral. Como observa Bruno Karsenti, a função do Legislador efetiva-se num plano que Rousseau considerava completamente ignorado pelos teóricos do direito natural clássico, isto é, "celle oú l'existence et l'action du peuple s'attestent d'um même geste". ${ }^{42}$ Nesta perspectiva, Karsenti entende o Legislador como um "faiseur de culture politique" $(2012,30)$. Para ele: "Le secret incompressible du législateur est d'abord que le peuple doit être secrètement travaillé dans le sens de la politique pour que la politique, pour lui, prenne un sens, qu'il puisse se dire peuple, et par là trouver en position de sujet dans l'élaboration de ses lois" (2012, 31). De fato, o legislador deveria "conduzir sem violência e persuadir sem convencer" (Rousseau, 2016, 94). Utilizando a terminologia fichteana podemos sugerir que a verdadeira função do Legislador é exortar. Nesta medida sua ação coincide com aquela do público erudito em Fichte. É justamente neste plano que acreditamos achar o significado mais profundo da política pensada segundo os princípios da Doutrina da ciência. 


\section{Bibliografia}

BAZZAN, M. R. e D'ALFONSO, M. V. (2020) "Da Perfectibilité à Bildsamkeit. A ascendência rousseauniana da antropologia de Fichte", CADERNOS DE FILOSOFIA ALEMÃ: CRÍTICA E MODERNIDADE, n.2, v.25, 13-32. doi: 10.11606/issn.2318-9800.v25i2p13-32.

BERTINETTO, Alessandro (2009) "Faktum und Genesis in der Wissenschaftslehre von 1804/II", in: GODDARD, J.-C. \& SCHNELL, A (ed.), L'Être et le phénomène. Sein und Erscheinung, Paris, Vrin, 85-96.

CANALE, Damiano (2001) La costituzione delle differenze. Giusnaturalismo e codificazione del diritto civile nella Prussia del '700. Giappichelli, Torino.

CESA, Claudio. "La posizione sistematica del diritto", in: MASULLO A. \& IVALDO M. (a cura di) (1995) Filosofia trascendentale e destinazione etica, Guerini Associati, Milano, 239-260.

DI PASCALE, Carla (1979)“Trasformazione sociale e restaurazione in Germania”, ANNALI DELL'ISTITUTO STORICO ITALO-GERMANICO IN TRENTO, v. 5, 143-205.

DUSO, G. (2001), "La philosophie politique de Fichte : de la forme juridique à la pensée de la pratique”, LES ÉTUDES PHILOSOPHIQUES n. 1, v. 56, 49-66.

FERRAGUTO, Federico. (2016), "Doutrina da ciência e arte de viver", REVISTA DE ESTUD(I)OS SOBRE FICHTE, v. 11 (conexão em 12 de dezembro 2020), URL: http:// journals.openedition.org/ref/647.

KANT, Immanuel (1992) A religião dentro os limites da simples razão. Tradução de Artur Muruão. Edições 70, Lisboa.

KARSENTI, Bruno (2012) Moïsé et l'idée du peuple, Editions du Cerf, Paris.

KOSELLECK, Reinhart (1972). "Einleitung", in: BRUNNER, Otto; CONZE, Werner; KOSELLECK, R. (hrsg.), Geschichtliche Grundbegriffe. Historisches Lexikon zur politischsozialen Sprache in Deutschland, Klett-Cotta, Stuttgart, [8 Vol. 1972-1997], V. 1, XII-XXVIII. FERRY, Luc \& RENAUT, Alain (1981) “Présentation”, in: FICHTE, J.G. Machiavel et d'autres écrits, Payot, Paris.

KAMMACHER, Klaus (hrsg.) (1981) Der transzendentale Gedanke. Die gegenwärtige Darstellung der Philosophie Fichtes, Meiner, Hamburg.

HÖLSCHER, Lucien (1978). Verbete: “Öffentlichkeit”, in: BRUNNER, CONZE, KOSELLECK: Geschichtliche Grundbegriffe. V. 4, 418-467.

MEYER, Alrich (1969) "Mechanische und organische Metaphorik politischer Philosophie”, ARCHIV FÜR BEGRIFFSGESCHICHTE, v. 13, 128-199.

ONCINA COVES, Faustino (1994) "Para la paz perpetua de Kant y el fundamento del derecho natural de Fichte: encuentros y desencuentros", DAIMON n. 9, 313-339.

ONCINA COVES (2003) "Wahlverwandtschaften zwischen Fichtes, Maimons und Erhards Rechtslehren", FICHTE-STUDIEN v. 24, 63-84.

RADRIZZANI, Ives (2006) "Fichtes «Eingreifen ins Rad der Zeit». Gibt es eine «Machiavellisierung» des Politischen beimspäten Fichte". In: MANZ, Hans-Georg von. \& ZÖLLER, G. Fichtes praktische Philosophie - Eine systematische Einführung, Olms, Hildesheim/Zürich/New York, 155-173.

RAMETTA, Gaetano (1995) Le strutture speculative della dottrina della scienza, Pantograf, Genova.

Revista de Estud(i)os sobre Fichte, 21 | 2020 
RAMPAZZO BAZZAN, M. (2006). "Das Ephorat bei J. G. Fichte”, FICHTE-STUDIEN v. 27, $117-133$.

RAMPAZZO BAZZAN, M. (2016) "Sobre la huella de Kant em la doctrina del derecho de Fichte", ESTUDOS KANTIANOS, Marilia, v. 4, n 1, 83-104 conexão em 1 de dezembro 2020 URL: https://revistas.marilia.unesp.br/index.php/ek/article/view/6149.

RAMPAZZO BAZZAN, M. (2017) Il prisma "Rousseau". Lo sguardo di Fichte sulla política tra Staatsrecht e Rivoluzione francese. Franco Angeli, Milano.

RAMPAZZO BAZZAN, M. (2019) "El enigma del Zwingherr", in: FERRER, D. A filosofia da História e da Cultura em Fichte, Coimbra University Press, Coimbra, 241-258.

RAMPAZZO BAZZAN, M. (2019) "O ponto nodal "Rousseau" na visão política de Johann Gottlieb Fichte", Doispontos, n. 1, v. 16, 24-39 (consultado em 19 de novembro 2020) URL: https://revistas.ufpr.br/doispontos/article/view/59735/39284.

RAMPAZZO BAZZAN (2019) “Fichte y el ejercicio de la Ilustración en Berlín”, REVISTA DE ESTUD(I)OS SOBRE FICHTE v. 18 URL:http://journals.openedition.org/ref/981.

REHBERG, August Wilhelm (1793) Untersuchungen über die Französische Revolution, Ritscher, Hannover/Osnabrück.

RENAUT, Alain (1986) Fichte et le système du droit. Philosophie et droit dans la pensée de Fichte, PUF, Paris.

ROUSSEAU, J.-J. (2016) Do Contrato social. Tradução de Eduardo Brandão. Companhia das Letras, São Paulo.

ROUSSEAU, Jean-Jacques (1972) Discurso sobre as artes e as ciências. Tradução de Antonio Robeiro. Abreu, Porto.

SCHIERA, Pierangelo (1975) "La Prussia fra polizia e «lumi»: alle origini del «Modell Deutschland", JAHRBUCH DES ITALIENISCH-DEUTSCHEN HISTORISCHEN INSTITUTS IN TRIENT, v. 1, 51-84.

SUAREZ, Carl Gottlieb von (1960) Vorträge über Recht und Staat. h. v. Hermann Conrad \& Gerd Kleinheyer. Westdeutscher Verlag, Köln/Opladen.

TORRES FILHO, Rubens (1973) “O discurso fichteano”, DISCURSO, 4(4), 9-40.

TORRES FILHO, R. (1975), O espírito e a letra. A crítica de imaginação em Fichte, Ática, São Paulo, 152; “Apresentação" in: FICHTE, J. G. (2012), Pensamento político de Machiavel, São Paulo, Hedra, 9-14.

ZÖLLER, Günter (2015). Leer a Fichte. Herder, Barcelona.

\section{NOTAS}

1. Para um detalhamento da sabedoria (Weisheit): Rametta, Gaetano (1995) Le strutture speculative della dottrina della scienza, Pantograf, Genova, 151-163.

2. Trata-se de uma expressão que Fichte utiliza na Anweisung zum seligen Leben com objetivo de diferenciar sua concepção da moral frente ao ‘legalismo' kantiano. Cf. ASL, GA I/9, 109. 
3. Como veremos mais para frente trata-se do "caráter político que Fichte confere à linguagem" ou da "escritura política" que ressaltou Rubens Rodrigues Torres Filho cf. Torres Filho, R. (1975), O espírito e a letra. A crítica de imaginação em Fichte, Ática, São Paulo, 152; “Apresentação" in: Fichte, J. G. (2012), Pensamento político de Machiavel, São Paulo, Hedra, 9-14, em part. 13.

4. Para um detalhamento sobre esta expressão cf. Ferraguto, Federico (2016) "Doutrina da ciência e arte de viver", REVISTA DE ESTUD(I)OS SOBRE FICHTE, v. 11 (conexão em 12 de dezembro 2020), URL: http://journals.openedition.org/ref/647.

5. "Es gibt zwei Möglichkeiten, sich mit Ihrem Beitrag auseinanderzusetzen. Einmal kann man ausgehen von der Frage, ob der Freiheitsraum, der bei Fichte im Staat dem einzelnen bleibt, nicht doch ein bisschen verkürzt dargestellt worden ist, und zweitens, was mir wichtiger erscheint, kann man ihn angehen von der anderen Frage, ob denn die Aporien die in so prägnanter Weise aufgewiesen worden sind, wirklich Fichte anzulasten sind, oder ob sie nicht im Wesen der Sache begründet liegen. "Diskussion Hahns Beitrag Fichtes Politikbegriff“; In: Hammacher, Klaus (hrsg.) (1981) Der transzendentale Gedanke. Die gegenwärtige Darstellung der Philosophie Fichtes, Meiner, Hamburg, 212.

6. De acordo com Schottky, a filosofia do direito de Fichte reproduziria de fato as aporias do paradigma jusnaturalista. Para um detalhamento cf. Duso, G. (1987) "Libertà e stato in Fichte: la teoria del contratto sociale". In: Duso (a cura di). Il Contratto sociale nella filosofia politica moderna, Il Mulino, Bologna, 1987, 273-309; Rametta, G. (2005) “Direito e poder em Fichte”. In: Duso, G. (ed) 0 poder. Pétropolis, Vozes, 284-304.

7. Schottky, Richard (1995) Untersuchungen zur Geschichte der staatsphilosophischen Vertragstheorie im 17. Und 18. Jahrhundert (Hobbes - Locke - Rousseau - Fichte) mit einem Beitrag zum Problem der Gewaltenteilung bei Rousseau und Fichte, Fichte Studien Supplementa, Amsterdam/Atlanta.

8. Para um detalhamento desta questão: De Pascale, Carla (1994). "La teoria e la pratica del diritto", DAIMON n. 9, 275-288; Duso, G. (1999) "La philosophie politique de Fichte: de la forme juridique à la pensée de la pratique", FICHTE-STUDIEN v. 16, 191-211; Vogel, Jean (2014) La réinvention de la théorie politique par Fichte, Editions de l'Université libre de Bruxelles, Bruxelles.

9. Tradução em português: Fichte, J.G. (2012) Fundamento do direito natural segundo os princípios da doutrina da ciência. Tradução e nota de José Lamego. Edição da Fundação Calouste Gulbenkian (=FDN).

10. Para um detalhamento sobre este ponto cf. Scattola, Merio (2003) Dalla virtù alla scienza. La fondazione e la trasformazione della disciplina politica nell'età moderna, FrancoAngeli, Milano, 510 et passim.

11. Torres Filho, Rubens (1973) “O discurso fichteano", DISCURSO, 4(4), 9-40, em part. 23.

12. Para um detalhamento cf. Rampazzo Bazzan (2019) "Fichte y el ejercicio de la Ilustración en Berlín", REVISTA DE ESTUD(I)OS SOBRE FICHTE v. 18 (consultado em 14 de novembro 2020). URL:http://journals.openedition.org/ref/981.

13. "Mas, uma vez que ele não encontra este Eu agente originariamente na consciência empírica, põe-o, mediante o único ato do arbítrio que lhe está permitido no seu ponto de partida (que é a decisão livre de querer filosofar) e a partir daí deixa-o continuar a agir, sob os seus olhos, de acordo com as suas leis próprias, que são perfeitamente conhecidas do filósofo" (GRN, GA 1,3, 317/FDN, 10).

14. Para um detalhamento sobre esta operação de genetização cf. Bertinetto, Alessandro (2009) "Faktum und Genesis in der Wissenschaftslehre von 1804/II", in: Goddard J.-C. \& Schnell, A (ed.), L'Être et le phénomène. Sein und Erscheinung, Paris, Vrin, 85-96.

15. Para um detalhamento deste aspecto com enfoque no curso sobre a doutrina do direito de 1812 cf. Rampazzo Bazzan M. (2016) "Sobre la huella de Kant em la doctrina del derecho de Fichte”, ESTUDOS KANTIANOS, Marilia, v. 4, n 1, 83-104 conexão em 1 de dezembro 2020 URL: https://revistas.marilia.unesp.br/index.php/ek/article/view/6149. 
16. Em uma carta datada em 29 de agosto de 1795 Fichte escreve para Reinhold que durante o verão ele haveria desenvolvido uma pesquisa sobre as doutrinas do direito dando-se conta que em elas falharia "uma verdadeira dedução da realidade do conceito de direito" (GA III/2, 385).

17. Do qual Fichte escreve uma resenha (Rez.Zef., GA 1/3, 221-228), publicada no Philosophisches Journal (n. 9, 1795, 81-92).

18. Para uma análise deste aspecto: Oncina Coves, Faustino (1994) "Para la paz perpetua de Kant y el fundamento del derecho natural de Fichte: encuentros y desencuentros", DAIMON n. 9, 313-339; Oncina Coves (2003. "Wahlverwandtschaften zwischen Fichtes, Maimons und Erhards Rechtslehren", FICHTE-STUDIEN v. 24, 63-84.

19. Sobre as ascendências rousseauianas da Bildsamkeit: cf. Bazzan, M. R. e D'Alfonso, M. V. (2020) "Da Perfectibilité à Bildsamkeit. A ascendência rousseauniana da antropologia de Fichte", CADERNOS DE FILOSOFIA ALEMÃ: CRÍTICA E MODERNIDADE, n.2, v.25, 13-32. doi: 10.11606/ issn.2318-9800.v25i2p13-32.

20. ZÖLLER, Günter (2015). Leer a Fichte. Herder, Barcelona, 56-57

21. Para um detalhamento: Schiera, Pierangelo (1975) "La Prussia fra polizia e «lumi»: alle origini del «Modell Deutschland", JAHRBUCH DES ITALIENISCH-DEUTSCHEN HISTORISCHEN INSTITUTS IN TRIENT, v. 1, 51-84; MEYER, Alrich (1969) "Mechanische und organische Metaphorik politischer Philosophie”, ARCHIV FÜR BEGRIFFSGESCHICHTE, v. 13, 128-199.

22. Canale, Damiano (2001) La costituzione delle differenze. Giusnaturalismo e codificazione del diritto civile nella Prussia del '700. Giappichelli, Torino, 117.

23. Suarez, Carl Gottlieb von (1960) Vorträge über Recht und Staat. h. v. Hermann Conrad \& Gerd Kleinheyer. Westdeutscher Verlag, Köln/Opladen, XXI. Para um detalhamento cf. DI PASCALE, Carla (1979) “Trasformazione sociale e restaurazione in Germania”, ANNALI DELL'ISTITUTO STORICO ITALO-GERMANICO IN TRENTO, v. 5, 143-205.

24. Cf. Fichte, Principien der Gottes-. Sitten- und Rechtslehre. GA II, 7, 379.

25. Para um detalhamento desta expressão cf. Zöller, G. (Hrsg.). Der Staat Mittel zum Zweck: Fichte über Freiheit, Rechts und Gesetz, Nomos, Baden-Baden.

26. Varios comentadores ressaltaram um progressivo abandono por parte de Fichte da logica jusnaturalista. foi o caso de: CESA, C. "La posizione sistematica del diritto", in: Masullo A. \& Ivaldo M. (a cura di),(1995), Filosofia trascendentale e destinazione etica, Guerini Associati, Milano, 239-260. Duso, G. (2001), "La philosophie politique de Fichte : de la forme juridique à la pensée de la pratique”, LES ÉTUDES PHILOSOPHIQUES n. 1, v. 56, 49-66. Para nós os pressupostos deste abandono já estão presentes nos escritos e cursos de Jena, embora sejam nos escritos posteriores que esta direção se torna mais explicita cf. Rampazzo Bazzan, M. (2017) Il prisma "Rousseau". Lo sguardo di Fichte sulla politica tra Staatsrecht e Rivoluzione francese. Franco Angeli, Milano.

27. Rudolf Steck, um aluno de Fichte, anuncia a seu amigo Samuel Ith a publicação do Fundamento do direito natural sustentando que aí Fichte "haveria cumprido com suas promessas adiantadas nas Prelações sobre o destino do erudito de 1794" e que "sua doutrina do direito seria destinada a abrir uma nova época" (FimG, 6/1, 201).

28. A esse respeito cabe lembrar que Fichte integra as críticas apontadas por Benjamin Erhard em sua resenha às Contribuições para retificar o julgamento do público alemão sobre a Revolução francesa, publicada no Philosophisches Journal em 1795. Para um detalhamento cf. Rampazzo Bazzan 2017, 274 et passim.

29. Cf. Renaut, Alain (1986) Fichte et le système du droit. Philosophie et droit dans la pensée de Fichte, PUF, Paris.

30. De fato, da posição do direito como elemento intermediário entre natureza e moral decorreram grandes confusões e mal-entendidos por parte de muitos comentadores. Um dos exemplos mais conhecidos é a tese de uma maquiavelização no pensamento de Fichte, avançada por Luc Ferry e Alain Renaut: (1981). "Présentation". In: Fichte, J.G. Machiavel et d'autres écrits, Payot, Paris, 12. Para uma crítica desta posição cf. RADRIZZANI, Ives (2006) "Fichtes «Eingreifen 
ins Rad der Zeit». Gibt es eine «Machiavellisierung» des Politischen beimspäten Fichte”. In: Manz, Hans-Georg von. \& Zöller, G. Fichtes praktische Philosophie - Eine systematische Einführung, Olms, Hildesheim/Zürich/New York, 155-173.

31. Esta exigência torna-se evidente nos escritos tardios especialmente nas conferências de 1813 (cf. Rampazzo Bazzan, M. (2019), "El enigma del Zwingherr", in: Ferrer, D. (ed.) A filosofia da História e da Cultura em Fichte, Coimbra University Press, Coimbra, 241-258). Nos escritos de Jena esta dimensão lida com a figura "eforos naturais" (cf. GRN, GA I/3, 457-458/FDN, 217).

32. "Para uma espécie de seres moralmente perfeitos não existe lei do Direito. Que o homem não pertence a esta espécie é algo que está já claro pelo facto de que tem de ser educado e educar-se a si próprio para a moralidade; porque o homem não é moral por natureza, mas é só pelo seu próprio labor que ele deve tornar-se moral" (GRN, GA I/3, 432/FDN, 178).

33. Cf. Koselleck, Reinhart (1972) "Einleitung", in: Brunner, Otto; Conze, Werner; Koselleck, R. (hrsg.), Geschichtliche Grundbegriffe. Historisches Lexikon zur politisch-sozialen Sprache in Deutschland, Klett-Cotta, Stuttgart, [8 Vol. 1972-1997], V. 1, XII-XXVIII.

34. Para um detalhamento: Hölscher, Lucien (1978). Verbete: “Öffentlichkeit”, in: Brunner, Conze, Koselleck: Geschichtliche Grundbegriffe, V. 4, 418-467 em part. 431 et passim.

35. Rehberg, August Wilhelm (1793) Untersuchungen über die Französische Revolution, Ritscher, Hannover/Osnabrück.

36. Cf. Kant, Immanuel (1992) A religião dentro os limites da simples razão. Tradução de Artur Muruão. Edições 70, Lisboa, 101 et passim.

37. ROUSSEAU, Jean-Jacques (1972) Discurso sobre as artes $e$ as ciências. Tradução de Antonio Robeiro. Abreu, Porto, 47.

38. Para um detalhamento desta questão: Rampazzo Bazzan, M. (2019) "O ponto nodal "Rousseau" na visão política de Johann Gottlieb Fichte", Doispontos, n. 1, v. 16, 24-39 (consultado em 19 de novembro 2020) URL: https://revistas.ufpr.br/doispontos/article/view/59735/39284.

39. Rousseau, J.-J. (2016) Do Contrato social. Tradução de Eduardo Brandão. Companhia das Letras, São Paulo, 92-93.

40. Trata-se de uma instituição inspirada pelo Tribunato de Rousseau. Para um detalhamento: Rampazzo Bazzan, M. (2006). “Das Ephorat bei J. G. Fichte”, FICHTE-STUDIEN v. 27, 117-133.

41. "Mas o que perdemos de um lado, recuperamo-lo com ganhos do outro; pois o Estado converte-se ele próprio no estado natural do homem e as suas leis não devem ser outra coisa senão o Direito natural realizado" (GRN, I/3, 432/FDN, 178).

42. KARSENTI, Bruno (2012) Moïsé et l'idée du peuple, Editions du Cerf, Paris, 2012, 28-29.

\section{RESUMOS}

This paper aims at discussing whether Fichte's concept of politics can be considered innovative for his time. Politics is an issue on which the philosopher has left us no systematic treaty. Thus, in order to answer the question raised, we have no choice but to go through the most significant definitions of politics scattered in his writings and conferences on the one hand; and consider his own engagement in both theory and practice as a man of culture, on the other one. Indeed, according to the interpretation we offer here for Fichte's thought, politics means not only the theory of the State (Staatslehre) or art of government (Regierungskunst) - what we call stricto sensu politics - but also the effects of the art of philosophy in society. In this perspective we propose to 
call political every effect of exhortation (Aufförderung) what we call latu sensu politics. Thus, politics according to the principles of the Doctrine of science would be not only knowledge (or technique), but much more an art of living in society.

ÍNDICE

Keywords: Politics, Fichte, Natural law, Social contract, German Idealism

\section{AUTOR}

MARCO RAMPAZZO BAZZAN

Universidade Federal do Espírito Santo (UFES) 